\title{
An Approach to the Acoustic Design of Outdoor Space
}

\author{
A.L. Brown \\ School of Environmental Planning \\ Griffith University, Brisbane, Australia \\ Lex.Brown@griffith.edu.au \\ and \\ Andreas Muhar \\ Institute of Landscape Architecture and Landscape Management \\ BOKU - University of Natural Resources and Applied Life Sciences, Vienna, Austria \\ Andreas.Muhar@boku.ac.at
}

\begin{abstract}
This paper focuses on soundscape planning, or acoustic design, in the planning and management of open space in both urban and non-urban areas. It is based on notions, promoted over several decades, that the acoustic aspects of open space can, and should be, subject to design in the same way as are the visual dimensions. The current paradigm for the management of the outdoor acoustic environment is noise control and soundscape planning needs to adopt quite different practices from noise control with respect to acoustic criteria and measurement. The paper explores the specification of acoustic objectives for outdoor soundscapes and the translation of these objectives into acoustic criteria that are amenable to measurement and prediction as part of the design process. Such objectives, termed Proposed Acoustic Environments, focus on the information content in sounds in a particular space and, only indirectly, on characteristics such as level or loudness. Outdoor acoustic design is mostly concerned with avoiding, or achieving, the masking of one set of information in the acoustic signal with other sets of information in the same signal. These are critical methodological issues if soundscape planning is to move from
\end{abstract}


being a good idea to common practice. The paper sets out the elements of a process for the acoustic design or management of outdoor space.

Keywords: soundscape, acoustics, noise, control, abatement, landscape architecture, open space, design, wilderness, recreation, planning

\section{INTRODUCTION}

\section{Background to the Acoustic Design of Outdoor Space}

This paper concerns sound in the planning and management of outdoor space. This may be constructed space - parks, squares, malls, residential precincts or other urban open space - or space in non-urban environments such as rural, wilderness or recreational areas. Since Schafer (1977) produced 'The Tuning of the World', the term soundscape (Truax, 1999) has entered the lexicons of a range of disciplines and educators interested in the acoustic environment, and it is the soundscape of these constructed or managed spaces that is of interest here. The soundscape of a place is simply its sonic, or acoustic, environment, with the receiver, or listener, at the centre of the sonic landscape (Porteous and Mastin, 1985). Schafer (1977) argued, amongst other matters, that soundscapes are amenable to analysis and design. To him, acoustic design meant discovering the principles by which the aesthetic qualities of the acoustic environment may be 
improved. These principles could include elimination or restriction of certain sounds through noise abatement, the preservation of sounds that give character or sense of place to a location (soundmarks as the acoustical equivalent of visual landmarks) or imaginative placement of sounds to create attractive and stimulating environments. In Hellström’s (2002) translation of Pascal Amphoux's work on the sonic identity of European cities, these three approaches are described as: defensive, protecting the sonic environment from acoustic pollution; offensive, consolidating the acoustic milieu and; creative, composing the sonic landscape.

Various authors link these principles to physical planning and design (for example, Hedfors and Grahn, 1998). Bohme (2000) argues that, “...city planning can no longer be content with noise control and abatement, but must pay attention to the character of the acoustic atmosphere of squares, pedestrian zones, of whole cities”, and others advocate (Anon, 1998):

- "Urban and landscape architects should take auditory perception into account. The perceptions of all senses should be dealt with to the same degree and the visual should not be favoured ... .

- Urban and landscape planners and designers should create sonic environments which form part of their context over both time and space..

- Design tools dealing with auditory aspects should be developed to fit into the process of urban and landscape planning and design ... ."

It is the latter of these entreaties that is the particular focus of this paper. While there is a growing interest in, and literature about, soundscapes, much of it has been high in vision but rather short in means for implementation. This objective of this paper is to move this conceptual field forward by providing a pragmatic approach for planners, landscape architects, engineers, 
acousticians and others involved in the planning and design of the built environment, and for managers of rural, natural and recreational landscapes. The approach is also relevant to those interested in public installations that may have an acoustic component (see, for example, Australian Sound Design Project, 2001).

\section{Soundscape Planning vis-a-vis Noise Control}

Acoustic design of outdoor space should be seen as complementary to noise management, abatement or control. Noise management is the current paradigm for management of the outdoor acoustic environment, involving a large body of knowledge, practice, law, policing and control activities and most municipal authorities, provincial governments, and even national governments, are active in this to varying degrees. In Europe, it has been estimated that around 20 percent of the Union's population, or close on 80 million people, suffer from noise levels considered unacceptable (European Commission, 1996). The complementarity of soundscape planning and noise control is best illustrated by three essential differences between them.

Firstly, noise control in urban areas deals largely with 'sounds of discomfort' (Augoyard, 1998) - sounds that disturb sleep, interfere with communication, distract or annoy people. Limits to these sounds are based on acceptable risk, and noise abatement seeks to minimise negative effects on people in high exposure situations. These negative effects are well known, as are the levels recommended to limit them (WHO, 2000). By contrast, soundscape planning focuses on acoustic environments that are regarded positively - that people prefer or consider as desirable 
environments. Historically, noise control has been little concerned with these types of acceptable noise environments. It is only in the particular case of internal room acoustics, and more recently with the emerging interest in Sound Quality for product design (Genuit, 2002), that noise criteria are based on acceptability or listening preference - in all other cases they are based on minimising the negative effects of noise (Truax, 1998). Noise criteria control some effect such as communication or sleep disturbance and have little direct application in the design of preferred acoustic conditions for outdoor space. The issue of suitable acoustic objectives, or preferred listening environments for soundscape planning of cities and countrysides, must be examined. An approach to this problem, in our opinion currently a major impediment to acoustic design of outdoor space in practice, is proposed in this paper.

Secondly, there is a difference between noise control and soundscape planning in the locus of application, though in this difference there is more overlap. Noise control uses three strategies for action: control at the source, management of the transmission path between source and receiver, and protection of the receiver. While noise control practice is active in each of these strategies, its aim is largely protection of people who are indoors, particularly in residential dwellings, from noise generated outdoors - road traffic and aircraft noise heard indoors, for example (exceptions are physiologically damaging noise in the workplace, noises generated in and between buildings and rooms and, to a very limited extent, noise in recreational and wilderness areas). By contrast to the focus on outdoor sound heard indoors, soundscape planning is likely to be the planning and management of sound heard in open spaces, though not exclusively so. 
The third difference is that, in noise control, sound is seen as a by-product, a waste to be managed. By contrast, soundscape planning approaches sound as a resource, one to be utilised and, as in the sustainable use of all resources, one whose depletion or degradation is to be avoided. Hedfors (2002) provides an example, in the context of rural landscapes in Sweden, of sound as a resource in planning and as an element of design. This resource-oriented view of sound is most easily appreciated in the context of wilderness or recreational areas, as illustrated by the US National Park Service (2000): “Preservation and restoration of diminishing natural sound environments or soundscapes has become a foremost challenge in the protection of park resources" and "Natural sounds are part of the special places we preserve. Rustling winds in canyons and the rush of waters in the rivers are the heartbeat and breath of some of our most valuable resources.” Sound can also be regarded as a resource, though rarely recognised as such, within cities, towns and rural areas. Quiet, generally thought of as the absence of sound, but much better thought of as a particular characteristic of sound, is a clear example of sound as a scarce resource in urban areas, but there are many other examples, such as sounds conveying a city’s identity (the chimes of Big Ben in London) and other sounds that form parts of a society's culture. In some cases, even noise can be utilised actively as a resource, for example through locating music clubs or discotheques close to noisy streets and thereby masking the noise from the music clubs with the traffic noise in an area already dominated by road traffic noise (see examples in Tillner, 2000). 


\section{Potential Applications for Soundscape Planning}

Notionally, the potential for the application of acoustic design to outdoor space is unbounded but, in practice, the opportunities are likely to be more constrained. The designer/manager is not faced with a blank sheet, but with spaces in cities and countrysides whose soundscapes are, to varying degrees, already dominated by the noises from surface and air transportation and from the activities that people conduct on or near these spaces and whose lifestyles and livelihoods depend on theses activities. Cities are vibrant places, and the sounds of transport, people, industry and commerce is part of that vibrancy. Most non-urban areas also have many of these sounds present, together with those of rural industries and recreation. Soundscape planning is not about quieting all these spaces. Instead, it is directed at special places where the opportunity may exist, through appropriate management of sound, to increase human enjoyment. Table 1 suggests where such opportunities may occur. However, even from this list, one needs a realistic appraisal of the potential for application. For example Kihlman and Kropp (2001) have demonstrated that it is unreasonable to expect low levels of traffic noise in most urban locations, significantly inhibiting the opportunity for alternative acoustic experiences.

\section{TABLE 1 ABOUT HERE}


Opportunities will be considerably higher where new space is being planned, existing space is being remodelled or reallocated, or traffic management schemes are contemplated. Here, the prospects of incorporating soundscape design may be considerable, compared with stand-alone attempts at remedial acoustic design of existing spaces. However, temporary events or installations may stimulate an increased awareness of the acoustic environment and thereby prepare the ground for future activities. Opportunities are also likely to be higher in national parks, recreational areas and similar, where managers have a wider range of powers and tools by which to control human activities.

\section{CRITERIA FOR THE ACOUSTIC DESIGN OF OUTDOOR SPACE}

\section{Acoustic Objectives for Outdoor Spaces}

Specification of the acoustic objective must be the first step for soundscape planning and management. We need to assume that there will be, for many situations and places, particular acoustic environments that will increase human enjoyment, well being, amenity, quality-ofexperience, or quality-of-life. This should not be a contentious notion. We have a similar notion about visual preference and incorporate these into design - whether for urban spaces or nonurban environments. For example, form and colour figure prominently as parameters in most design processes and there is an accumulation of knowledge regarding what would, and would 
not be, good visual design practice. The authors in no way underestimate the complexity of most soundscapes, nor the conflicting and contradictory opinions that will be found, but, putting aside the important issue of the diversity of preferences that will exist amongst different individuals and groups of people (for visual, acoustic, or any other dimension of a place), what guidance exists regarding specification of acoustic objectives for outdoor environments?

Preferred acoustic environments outdoors has had little attention from the scientific community to date, primarily because of the over-riding emphasis in acoustic research on environmental noise. For example, there is copious data collected over decades on What noises do you hear around here? or What noises annoy you the most? (even as long ago as the New York Noise Abatement Commission, 1930) but very little on What sounds do you enjoy/prefer to hear in this place? A study in Yokohama (Tamura, 2002) is an exception, reporting not only sounds (outdoor sounds heard indoors) that were observed by and were annoying to residents, but also sounds that they found favourable. Sounds regarded as favourable included the twittering of birds and sounds of insects and frogs, the sounds of festivals and fireworks, wind movement in trees and grasses, wind chimes, bells of temples and churches, whistles of ships and the sounds of streams and sea waves. Favoured sounds were mainly natural sounds and some specific cultural sounds, and distinct from sounds that people did not prefer. Sasaki (1993) also sought to measure opinions on outdoor sounds that people preferred in urban areas, with somewhat similar results. While his methodology had significant limitations, including relying on surveying respondents away from the context of their own homes, his results are a salutary reminder of the diversity of opinion that will always exist, showing that, for any particular sound, individual 
responses were widely distributed across the like/dislike scale, though the modal response shifted markedly between different sounds.

Other scientific investigations into perceived quality of soundscapes include Berglund et al (2001) and Berglund and Nilsson (2001). Their work, in residential areas, is directed towards new tools to measure the way people perceive soundscapes, including sound-source identification, quantification of loudness, and attribute profiling of sound quality. Some of their field results suggest labelling soundscapes in residential areas in four ways: adverse, reposing, affective (inducing feelings or emotions) and expressionless. There is also interest in Sweden (Skanberg and Ohrstrom, 2002) in perceived quality of soundscape with respect to understanding how preferred soundscapes (particularly access to quiet in courtyards) can be supportive of health and well being. Carles et al (1999) concluded that further research into soundscape preference is required, after reporting the results of their laboratory study of the interaction between visual and acoustic stimuli on perception of the pleasantness of environment. Using images and sounds covering natural and semi-natural scenes and urban green spaces, they concluded that natural sounds, particularly of water, create positive feelings towards the landscape, but they also reported the importance of sound-image congruence in shaping environmental preference. In certain environments, any acoustic disturbance can lead to a rapid deterioration in environmental quality, but natural sounds may improve the quality of built-up environments to some extent.

While these research results are in no way counter-intuitive, to date they provide little guidance to any prospective designer/manager of outdoor space. How then to set acoustic objectives? The 
solution, we suggest, is to depart radically from the nature of most acoustic criteria in practice (which are almost exclusively based on overall sound level set to limit unwanted human responses) and instead to adopt acoustic objectives for soundscape design based on the information content of sounds. We postulate, in Table 2, acoustic objectives of this sort for different outdoor spaces. The is a personal list, based on experiences and intuition, but it does embody much of the observation, opinion, and commentary found in the soundscape literature to date, and in the limited research regarding human acoustic preference. Most of the objectives in Table 2 relate to natural sounds, particularly the sounds generated by wind, by moving water, or by animals, or to ensuring human sounds predominate over mechanical or amplified sounds. They also relate to good communication environments for speech or music or to geographical or cultural identity of place. Some relate to ‘quiet’ situations; others to vibrant, 'noisy’ places.

\section{TABLE 2 ABOUT HERE}

This list should cover the majority of outdoor spaces where acoustic design or management is appropriate. It includes, for example, objectives for urban spaces where one may wish to provide respite from the sounds of traffic $(\mathrm{c}, \mathrm{g})$, for parks or gardens that include water structures or specific acoustic installations (a,d,i), for spaces that are intended for speech or musical communication (g,h), for amenity in pedestrianised areas of both old and new cities and villages $(c, g)$, and for wilderness (d,f) and outdoor recreational areas (e). Identity of place (b,j,k) may be appropriate in both cities and rural areas. Identities may include, say, the pealing of a bell, the 
call to prayer from a mosque, the lowing of cattle or the tinkling of sheep bells, or motor vessels moving along canals.

It must be emphasised that these objectives have been carefully crafted to specify only the information content in the sounds to be heard in the particular place. They deliberately do not specify other acoustic dimensions (loudness, for example) though it will be shown below that acoustic dimensions that must eventually be available for design can be derived from the information content objectives and the specific site context. Specification of the information content ensures there is absolute clarity as to the intent. For example, objective (a) moving water should be the dominant sound heard, is unambiguous and appropriate both for a space intended for peace and tranquillity where the users can hear the quiet murmuring of a brook or the trickle of a water structure, and for a space intended for appreciation of the forces of nature in the crash of waves on a cliff or the thunder of a waterfall. Similarly, objective (g) suitable to hear unamplified speech (or music), applies equally to a bench in a park, to a pedestrian thoroughfare where buskers may be encouraged to locate, or to space for dining alfresco. The lack of ambiguity in acoustic objectives specified in this way is designed to assist in planning and design. The objectives use a language that is common to everyone, a far cry from the complex technical jargon used by acoustic specialists. In this way the objectives for a space can be debated, alternatives suggested, and compromises reached, yet they provide outcomes that are not in the least acoustically equivocal, and ones that are suitable to write directly into design or management briefs. The loudness of the different sounds, their duration, the reverberant characteristics of the space, the nature of surface materials to be used, the potential to control source levels or to provide attenuating structures etc, are then matters that acoustic specialists 
can subsequently attempt to manipulate, once the objective is agreed, to achieve the desired outcome.

Table 2 provides a starting point for designers and managers to use in practice. While the list is likely to be reasonably comprehensive, we would encourage debate about its utility and universality, suggested additions, and further research to test, and modify, its robustness. We suggest that the acoustic objectives of this type be referred to in the design or management process as the Proposed Acoustic Environment for a particular place and context. They are our response, in soundscape design, to counter the legacy of decades of noise control approaches on which Bohme (2000) comments “... it is a matter of overcoming the narrow natural science based approach which remains at best capable of grasping noise as a function of decibels, and to ask instead what type of acoustic character the spaces in which we live should have." In part it also addresses Smith’s (1994) (quoted in Ingham et al, 1999) concern that soundscape work needs to listen in context.

\section{Translating Proposed Acoustic Environments to Measurable Acoustic Parameters}

Specifying Proposed Acoustic Environments is not a trivial exercise. Unambiguous specification of the objective in this way is a critical starting point for establishing quantifiable acoustic parameters that can be measured, predicted and assessed as part of acoustic design. It needs to be recognised that each objective in Table 2, while the essence of simplicity in intent, is actually a statement about a quite complex acoustic outcome concerning two components of sound within 
the space - the wanted signals and the unwanted signals. They recognise that these two sound components are present, specifying the sound that we want (or in some cases the sounds that we do not want) but implicitly recognise that other sounds will also be present. The statements also indicate the required relationship between these different sound signals.

The context obviously dictates whether a sound is wanted or not wanted, and in different contexts the same sound may be one or the other. For example, in a pedestrian mall, the Proposed Acoustic Environment may be hear (non-mechanical, non-amplified) sounds made by people. Here, the sounds of voices and footsteps may be wanted, but amplified music and traffic noise is likely to be unwanted, and the design would ensure that the former were not masked by the latter. By contrast, for a space intended for contemplation or reflection, the Proposed Acoustic Environment may be not be able to hear the sounds of people. Here the sounds of voices and footsteps would be unwanted, and the design would aim to ensure that no voices or footsteps were present, or that these were masked by some other acceptable sound.

In summary, for every context, specification of the Proposed Acoustic Environment enables one to disaggregate:

- the wanted sounds (for example, church bells, sounds of nature, sounds of city vitality, footsteps, sounds of running water, music, etc); and

- the unwanted sounds (for example, road traffic, human sounds, amplified music, machinery noises, etc).

In some circumstances there may also be sounds to which one is indifferent (say incidental bird calls) but these can simply be included in the wanted category. It is this requirement for 
disaggregation of sound by sources in soundscape planning that is a specific, and critical, divergence between it and the traditional approaches to noise measurement and assessment. However, this does create a significant difficulty in measurement.

Most acoustic descriptors common in noise management have no interest in, and make no recognition of, the information content in the sound. They measure the overall level and loudness of all the sound present at a specific location. Noise scales that rely on concepts such as equivalent continuous sound level ( $\mathrm{L}_{\mathrm{eq}}$ and $\mathrm{L}_{\mathrm{den}}$ (Schwela, 2001)) simply integrate all the sound signals present, irrespective of their source. Scales based on exceedance levels (such as $\mathrm{L}_{10}$ and $\mathrm{L}_{90}$ (Cunniff, 1977)) are equally non-discriminatory with respect to different sound sources. While microphones faithfully transduce, and tapes faithfully record, the sounds that are present, immediately these signals are processed through most noise measurement equipment used for assessment (sound level meters, level recorders, and noise level analysers - all of which measure only the level of the sound), all source discrimination is lost. Berglund and Nilsson (2001) have previously commented on the inappropriateness of conventional noise measurements for soundscape planning.

A new approach is required in the measurement of sound in outdoor space that differs from that used in noise control, one that separately assesses the wanted sounds and the unwanted sounds. At present there is nothing in planning practice for acoustic design of outdoor situations akin to what is available for visual simulations where the use of realistic renderings is already a standard in the communication process between planners, clients, and the public. 


\section{AN APPROACH TO ACOUSTIC DESIGN OF OUTDOOR SPACE}

With these principles in mind, it is appropriate to suggest a design approach for soundscape planning and management, equally applicable for urban or non-urban area, and independent of the scale of the planning or management activity (Figure 1).

\section{FIGURE 1 ABOUT HERE}

The first step is to establish the activities that will occur at the site under consideration.

Depending on the scale, there might be only one activity that is intended, say relaxing in a small city square, but most sites will likely cater for a range of activities in which case zoning of the site into different activities will be appropriate. For example, a ski-field is likely to have many appropriate activity zones: ski village zone, on-piste and off-piste zones, eating areas and disco areas. Zoning could occur spatially, or temporally. Examples of the latter may be a park that might normally be a meeting place, but at other times a market, or the site for an outdoor concert. The concept of zoning is well established in most design professions and amongst recreational area planners. It may be that zoning for acoustic environments may not be contiguous with zoning undertaken for other planning purposes, in which case additional zones may need to be established as a result of the overlay of zones.

The second step establishes Proposed Acoustic Environments for each zone. These objectives should be of the type suggested in Table 2. It is not appropriate here to specify a methodology 
for doing this, but clearly good planning practice would include consultation procedures so that diversity of needs and interests were considered. It might be the case that Proposed Acoustic Environments expressed by different user groups are incompatible or even mutually exclusive. If no compromise can be found at this stage, a revision of the zoning or even of the activities (see step one) may be necessary. The advantage of our approach, however, is that objectives described in this way are suitable for debate (compared to, say, acoustic objectives being put forward in the form of "the $L_{\text {Aeq,1h }}$ of the site should be less than $55 d B$ ", or as tenuous concepts such as "the site should be quiet and relaxing."). No specialist acoustic input is required to this point in the design approach, but is in subsequent steps.

The third step requires identifying the sounds that are wanted and the sounds that are not wanted at the site. This includes the sounds that are already present at a site, but also requires description of those sounds that will be present when the intended design or management is in place. For most situations this is a quite manageable task, and is likely to be achieved by site inspection. However it does require care. Experience shows that listening to and identifying all the sounds present in a particular environment is a skill that needs to be enhanced. Schafer (1977) has described the process of "ear cleaning", and he and others encourage the activity of sound walks to develop such skills (for example, Westerkamp 1974, Peterson 1966). Site inspection needs to adopt the best practice of sound walks (Dietze, 2000). For both wanted and unwanted sounds, diurnal and seasonal variations in the sounds need to be considered. Traffic sound levels vary throughout the day and night; insect, bird and other animal sounds vary seasonally; and summer and winter sounds may be completely different, particularly in colder climates where there is snow. 
In the fourth step, the magnitude, time variation, and other acoustical characteristics of each of the wanted and unwanted sounds in the current situation need to be separately measured or otherwise assessed. This is not always a simple task, but able to be undertaken using the existing toolbox of the acoustic specialist. Given the inability of most conventional noise measurement equipment to discriminate between different sounds, on-site measurement is useful only if a particular sound is the dominant one at that site, or if situations can be found in which the different sounds can be turned off and on to enable measurement - often considerable ingenuity is required to do this. Sound Level recording of the wanted sounds, a technique showing a graphical time-history of sound levels, overlayed by a separate time-history of the unwanted sounds, is an effective way to grapple with the time variation of the sounds under investigation.

In the fifth step, design options have to be studied for managing either the wanted or unwanted sounds, or both, to achieve the Proposed Acoustic Environment. This may involve eliminating or controlling the unwanted sounds using standard noise control techniques, or maintaining, enhancing or generating the wanted sounds. Techniques for the latter depend on the context, but could, for example, include increasing the extent, intensity, or air entrainment of running water in a design (where the objective is to have the sound of water dominant), changing the surfaces on which people walk (where the objective is hear sounds made by people), amplification of the sound of an acoustic installation, or increasing the provision of planting as suitable habitat for birds (where the objective is to hear the sounds of nature). Noise control of the unwanted sounds too depends on context, but in urban areas is most likely to require the elimination or reduction of noise from road traffic, the control of sounds from mechanical installations or amplified 
music, or minimisation of the sounds of people. In non-urban areas, control is likely to be required of the noise of individual vehicles, including motorised recreational vehicles, of mechanical equipment such as chain saws, and again of the sounds of people. All of the techniques of noise abatement for the control of the unwanted sounds are appropriate. Control techniques of relocating, repositioning, or changing the time of the source, are likely to have significant application.

As part and parcel of this step, the effects of each design option have to be predicted and assessed by comparing the future levels and other acoustic characteristics of the wanted sounds and the unwanted sounds. Obtaining the data for this step is similar to that of step four, but now must include estimation of the characteristics of sounds that are not already present or that will be modified as part of the design options. Measurement of equivalent sources at other sites is often possible, and there are methods for estimating sound levels at different distances from a known source level through noise modelling approaches. Mathematical predictions are possible for sources of sound that are point sources or line sources and Brown and Rutherford (1994) illustrate such modelling in the case of water structures in urban areas.

Continuously developing techniques such as virtual reality (VR) modelling have considerable potential to assist in this phase of soundscape design. So far, high-end realistic acoustic simulation (auralisation) systems have mainly been developed for designing indoor acoustic environments such as lecture theatres and concert halls (Savioja, 1999). At a much lower quality level, yet suitable for the communication within a planning process, simple applications are now possible using the standardised VR modelling languages VRML97 and X3D (Web3D 
Consortium, 2003). By using a library of sound sources, and locating these sources of both wanted and unwanted sounds over a virtual design space with appropriate decay functions as the sounds propagate from their sources, it is possible to move over the design space and hear the resultant sound and the effectiveness of the masking of the unwanted sounds by the wanted sounds. This is particularly effective if the sound sources are able to reflect the time-varying nature of most sound sources heard in the outdoor environment.

The nature of the assessment of the wanted and unwanted signals warrants further discussion. Most of the Proposed Acoustic Environments require that wanted sounds not be masked by the unwanted sounds (or in some cases this is more appropriately described as ensuring that the wanted sounds mask the unwanted sounds). Masking occurs when the sounds we wish to hear are rendered inaudible by other sounds. Masking is a very complex phenomenon determined not only by the relative levels of the masking and masked sounds (the so-called wanted signal S to unwanted noise $\mathrm{N}$ ratio $\mathrm{S} / \mathrm{N}$ ), but by the frequency spectrum of both the wanted and unwanted sounds, and by the temporal variation of both (Webster, 1984). Very roughly, a wanted signal will be first detected against an unwanted broadband signal when its level is less than $10 \mathrm{~dB}$ below that of the octave band level of the unwanted signal, and will mask the unwanted signal when it is some $10 \mathrm{~dB}$ above it. Smaller $\mathrm{S} / \mathrm{N}$ ratios are required to achieve masking where the frequencies of the wanted signal are less than $500 \mathrm{~Hz}$. While the complexity of the masking phenomenon is not examined further in this paper, an acoustician could calculate the extent of masking in practical soundscape design situations provided that the frequency spectra of both the wanted and unwanted sounds are available. 
Because of the time-varying nature of most sounds, the assessment of the masking of one sound by another will have to take the temporal patterns into account. For example, if a wanted sound was to mask the noise of road traffic, masking of the troughs of the road traffic noise may be possible, but masking of the peaks may not be (the difference between the troughs and peaks of road traffic can be quite variable - only a few decibels if the source of road traffic noise is distant, but 10 or $15 \mathrm{~dB}$ if the source of road traffic noise is close to the site of interest). Proposed Acoustic Environments in Table 2 have included modifiers such as "the dominant sound heard" or "the only sound heard" in their definitions to provide qualitative guidance in this assessment where the masking may not be complete. Further research into human preference for soundscapes in time-varying noise environments is necessary to provide more assistance to designers faced with this common complexity.

The whole process described in Fig. 1 is not a linear procedure, and several feedback loops have been included. For example, as a consequence of the final assessment, a revision of the design options might become necessary. It might even be the case, if no design option is able to fulfil the requirements stated in the specification of the Proposed Acoustic Environment, that the original zoning has to be revised. 


\section{SOUNDSCAPES AND THE EU DIRECTIVE ON NOISE}

Because acoustic design of outdoor space has had little attention from the authorities to date, it is interesting to note that, within the European Union, a mandate for some aspects of soundscape planning has been provided by Directive 2002/49/EC (European Union, 2002). The Directive provides a common approach to assessment and management of environmental noise across the EU and includes four elements of harmonisation of noise indicators and assessment methods, mapping of noise exposure, the preparation of action plans and informing and consulting residents. At first sight the Directive fits firmly within the traditions of noise control, but closer examination shows that it also contains elements that have some bearing on soundscape planning - it refers not only to the quieting of already noisy areas, but also to the protection of quiet areas against increases of environmental noise (Garrity, 2002). Specific aspects of the Directive have relevance to soundscape planning:

- $\quad$ strategic noise mapping must be undertaken (for all cities over 250,000 population by 2007, and over 100,000 by 2012);

- action plans on environmental noise should aim to preserve environmental quality where it is good;

- $\quad$ areas to which the directive applies include “... public parks or other quiet areas in an (urban) agglomeration, in quiet areas in open country ...."

- quiet area in open country means an area that is “... undisturbed by noise from traffic, industry or recreational activities”. 
Two points are worthy of elaboration. Firstly, the mapping that is required under the Directive can be a useful screening tool for identifying strategic opportunities for soundscape planning in urban and non-urban areas. While noise mapping has been common practice for decades, the emphasis on mapping immissions (exposure) compared to the mapping of noise emissions (Brown and Affum, 2002) is a critical change in emphasis. For example, the Birmingham Noise Mapping project (DEFRA, 2000) undertaken as something of a test case for the Directive, provides detailed maps down to grid of ten metres over a large urban area using a Sound Immission Contour Mapping (SICM) system. While produced primarily to identify noise hot spots and to assist in the estimate of population exposure, the level of detail available can also be used to identify locations where there is potential for soundscape planning. The Birmingham experience is being extended to London and then England (DEFRA, 2002).

Secondly, to the extent that action plans are to be prepared to preserve environmental quality where it is good, the Directive provides policy support for soundscape planning approaches within municipalities and regions, initially within the European Community, but with developing experience there, potentially in other places too. As an example of its influence, the Irish Environmental Protection Agency has begun a study to monitor the soundscape of relatively untouched wilderness areas in Ireland over time. The project recognises that soundscapes are a resource, that the monitoring is the first step to preparation of environmental quality objectives in 'relatively quiet areas' and that, in the longer term, land use plans will have to be acoustically designed (Institution of Engineers Ireland, 2002). 
However, while these steps in the formal recognition of soundscapes are valuable, measurement systems embedded in them are still based on integrative acoustic measures of the overall level of sound, and do not embrace the information content of sound approach described in this paper.

\section{CONCLUSIONS}

The vision for acoustic design of open space has been well established for several decades, but to date there appears to have been little attempt to implement this vision, at least amongst those best positioned to do so - planners, landscape architects, engineers, acousticians and others involved in the planning and design of the built environment, and managers of rural, natural and recreational landscapes. The immediate need is to educate designers and managers of open space about both the need and potential for consideration of the acoustic environment as an integral component of the planning process. This paper has provided a pragmatic approach to soundscape planning for both design of urban space and management of rural, recreational and wilderness areas. For a particular site, context and activity, specification of a Proposed Acoustic Environment as the acoustic objective is possible, and this is the starting point to break down the acoustic complexity of most sites to a problem amenable to control techniques and management strategies for individual sounds. Through the approach described, urban space designers and non-urban land managers will be able to communicate, and work co-operatively, with acoustic specialists. This is in contrast to the current situation in noise control and abatement practice where most acoustic tools, measurement techniques and criteria, largely shaped by the 
convenient energy-averaging capabilities of modern acoustic equipment, has little that is relevant to the open space designer/manager.

Acoustic design has the potential to capture imaginations. If acoustic environments that people prefer can be implemented using the procedures described in this paper, they may provide the catalyst for a much-needed wider interest, and reinvigoration, in managing urban and countryside noise problems.

\section{ACKNOWLEDGEMENTS}

This work was initiated while the first author was a guest Professor at BOKU University, Vienna and the support of that institution is acknowledged. Bernard Berry, of Berry Environmental Ltd UK, kindly provided comments on an earlier draft, and parts of the material were first presented at the World Forum for Acoustic Ecology Conference, Melbourne, March 2003.

\section{REFERENCES}

Anon (1998) Sonic Urban and Landscape Architecture. World Forum for Acoustic Ecology Web Site. Available http://interact.uoregon.edu/MediaLit/WFAE/noise/landscape.html [13 November 2002].

Augoyard, J.-F. (1998) The cricket effect. Which tools for the research on sonic urban ambiences? Papers presented at the "Stockholm, Hey Listen!” Conference, June 9-13. pp1-7, The Royal Swedish Academy of Music.

The Australian Sound Design Project [Online] (2001). Available: www.sounddesign.unimelb.edu.au/web/ [13 November 2002].

Bohme, G. (2000) Acoustic atmospheres: a contribution to the study of ecological aesthetics. Soundscape: The Journal of Acoustic Ecology 1 (1) 14-18. 
Berglund, B., Eriksen, C.A. and Nilsson, M.E. (2001) Exploring perceptual content in soundscapes. In E. Sommerfeld, E., Kompass, R. and Lachmann T. (Eds.), Fechner Day 2001. Pabst Science Publishers: Lengerich.

Berglund, B. and Nilsson, M.E. (2001) An attempt to capture the perceived soundscape. In Abstracts from NOPHER 2001: An International Symposium on Noise Pollution \& Health. Institute of Laryngology \& Otology, University College London.

Brown, A.L. and Affum, J. (2002) A GIS-based environmental modelling system for transportation planners. Computers, Environment and Urban Systems 26 577-590.

Brown, A.L. and Rutherford, S. (1994) Using the sound of water in the city. Landscape Australia 2, 103-107.

Carles, J.L., Barrio, I. L. and de Lucio, J.V. (1999) Sound influence on landscape values. Landscape and Urban Planning, 43(4) 191-200.

Cunniff. P.F. (1977) Environmental Noise Pollution, Wiley: New York. p130.

Department of Environment, Food \& Rural Affairs (2000) A Report on the Production of Noise Maps of the City of Birmingham. Available:

http://www.defra.gov.uk/environment/noise/birmingham/report/index.htm [20 April, 2003].

Department of Environment, Food \& Rural Affairs (2002) England noise mapping starts in London. Available: http://www.defra.gov.uk/news/2002/021212a.htm [20 April, 2003].

Dietze, L. (2000) Learning is living: Acoustic Ecology as pedagogical ground. Soundscape: The Journal of Acoustic Ecology 1 (1) 20-22.

European Union (1996) Future noise policy - European Commission Green Paper. COM (96)540, November.

European Union (2002) Directive 2002/49/EC of the European Parliament and the Council. Assessment and management of environmental noise. Official Journal of the European Communities, L189/12-L189/25. Available: http://europa.eu.int/comm/environment/noise/home.htm [6 May, 2003].

Garrity, T. (2002) Environmental Noise Directive. Environmental Health Journal, September, 280-281.

Genuit, K. (2002) Sound quality aspects for environmental noise. Proc Inter-Noise, Dearborn, Michigan. August.

Hedfors, P. (2003) Site soundscapes: Landscape architecture in the light of sound. Doctoral thesis, Swedish University of Agricultural Sciences: Uppsala. 
Hedfors, P. and Grahn, P. (1998) Soundscapes in urban and rural planning and design. In Schafer, R.M. and Järviluoma , H.(eds.) Northern Soundscapes - Yearbook of Soundscape Studies, 1, 67-82. Dept. of Folk Tradition Publication: Tampere.

Hellström, B. (2002) The sonic identity of European Cities: a presentation of the work conducted by the Swiss-French researcher Pascal Amphoux. In Järviluoma, H. and Wagstaff, G. (eds) Soundscape Studies and Methods, Finnish Society for Ethnomusicology: Helsinki.

Ingham, J., Purvis, M. and Clarke, D.B. (1999) Hearing Places, making spaces: sonorous geographies, ephemeral rhythms, and the Blackburn warehouse parties. Environment and Planning D: Society and Space. 17 283-305.

Institution of Engineers Ireland (2002) Noise Management. Journal of the Institution of Engineers of Ireland, July-August.

Kilman, T. and Kropp, W. (2001) City traffic noise - a local or global problem? Noise Control Engineering Journal, 49(4) 165-169.

Noise Abatement Commission (1930) City Noise. Department of Health, City of New York. The Academy Press: New York.

Peterson, I. (1966) Sounds of the season: learning to pay attention to the sounds around us. Science News, Dec 21. 150 (25-26).

Porteous, J.D. and Mastin, J.F. (1985) Soundscape. Journal of Architectural and Planning Research, 2, 169-186.

Sasaki, M. (1993) The preference of the various sounds in environment and the discussion about the concept of soundscape design. Journal of the Acoustical Society of Japan (E) 14(3),189-195.

Savioja, L. (1999) Modeling Techniques for Virtual Acoustics, Doctorate thesis, Helsinki University of Technology. Available: http://www.tml.hut.fi/ las/publications/thesis/thesis.pdf [24 April 2003].

Schafer, R.M. (1977) The Tuning of the World. Alfred A. Knopf: New York.

Schwela, D.H. (2001) The new World Health Organization guidelines for community noise. Noise Control Engineering Journal, 49(4), 193-198.

Skanberg, G. and Ohrstrom, E. (2002) Adverse health effects in relation to urban residential soundscapes. Journal of Sound and Vibration, 250(1), 151-155.

Smith, S.J. (1994) Soundcsape. Area, 26, 232-240.

Tamura, A. (2002) Recognition of sounds in residential environments: An indicator of our ambiguous sound environments. Journal of Asian Architecture and Building Engineering 1(2). 
Tillner, S. (2000): Vienna Urbion - Urban Intervention Gürtel West. Vienna City Administration, City Planning Department (MA18), Vienna, Austria.

Truax, B. (1998) Models and strategies for acoustic design. Papers presented at the "Stockholm, Hey Listen!” Conference, June 9-13. pp8-16, The Royal Swedish Academy of Music.

Truax, B. ed (1999) Handbook of Acoustic Ecology, $2^{\text {nd }}$ edition. Available:

http://www.sfu.ca/sonic-studio/handbook/ [4 April, 2003].

Web3D Consortium (2003): X3D Draft Specifications and VRML97 International Standard.

Available: http://www.web3d.org/fs_specifications.htm [24 April, 2003].

United States National Park Service (2000) Sound Waves: A Soundscape Newsletter. Available: http://www.nps.gov/bisc/soundwaves.htm [16 March 2003].

Webster, J.C. (1984) Noise and Communication. In Jones, D.M. and Chapman, A.J. eds. (1984) Noise and Society. Wiley: Chichester.

Westerkamp, H.(1974) Soundwalking, Sound Heritage, 3(4) Provincial Archives, Victoria, B.C.

WHO (2000) Guidelines for community noise. Berglund, B., Lindvall, T., Schwela, D. and Goh, K.T. World Health Organisation, Geneva, Ministry of the Environment, Singapore. 
Figure 1. An approach to the acoustic design of outdoor space

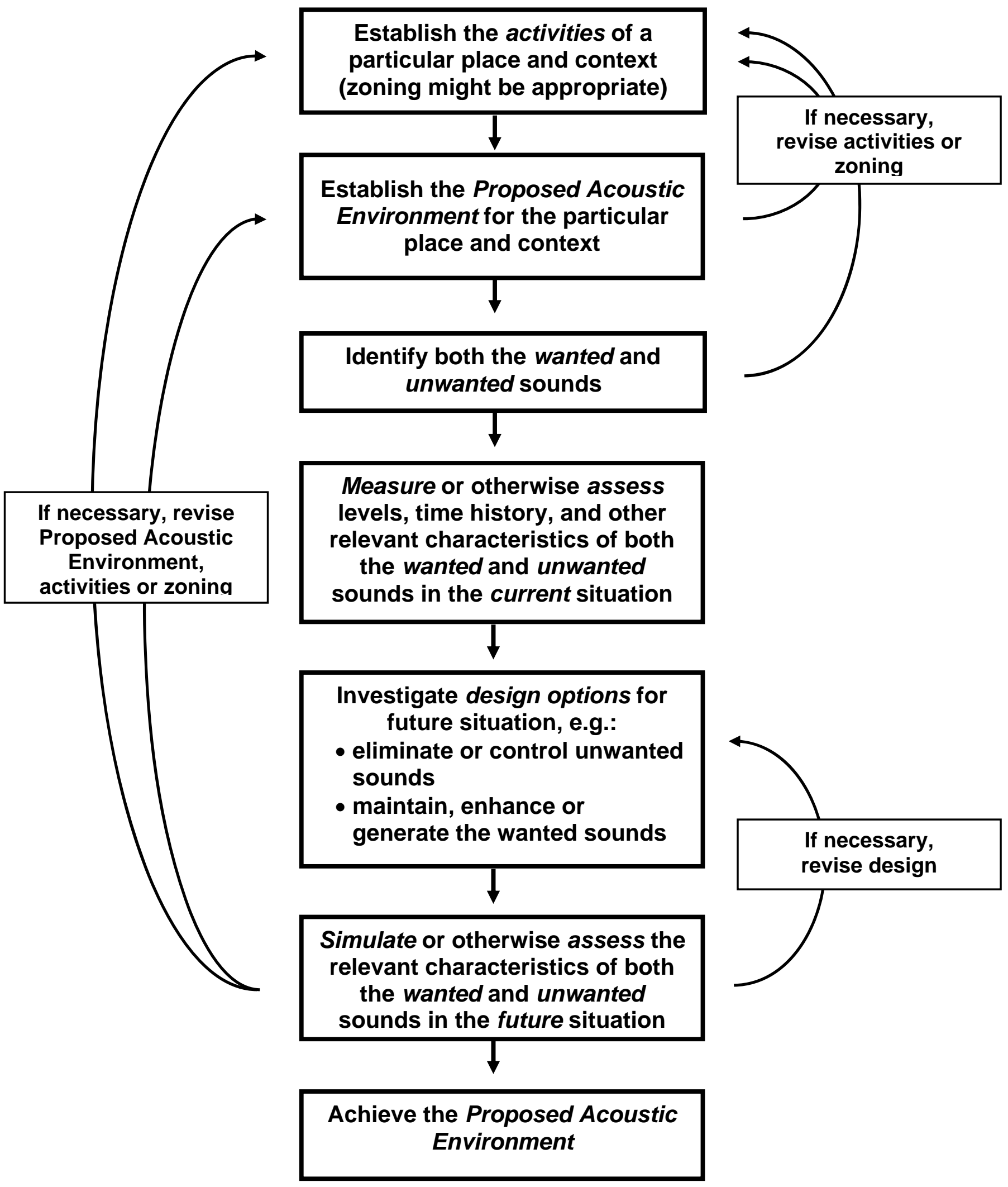


Table 1. Spaces where there may be opportunities for soundscape planning

\begin{tabular}{|c|c|c|}
\hline & Urban Space & Non-Urban Space \\
\hline $\begin{array}{l}\text { Constructed } \\
\text { and Other } \\
\text { Spaces }\end{array}$ & $\begin{array}{l}\text { parks and gardens } \\
\text { squares } \\
\text { malls } \\
\text { dwelling and apartment precincts } \\
\text { pedestrianised areas } \\
\text { sites of religious worship and } \\
\quad \text { meditation } \\
\text { heritage precincts } \\
\text { thoroughfares } \\
\text { meeting places } \\
\text { locations for: } \\
\quad \text { water structures } \\
\quad \text { sound installations } \\
\quad \text { outdoor speech or music } \\
\quad \text { venues } \\
\text { river banks } \\
\text { waterfronts } \\
\text { markets }\end{array}$ & $\begin{array}{l}\text { recreation sites such as } \\
\quad \text { ski fields } \\
\quad \text { golf courses } \\
\text { walking trails } \\
\text { pastoral and agricultural areas } \\
\text { cultural sites } \\
\text { beaches } \\
\text { national parks } \\
\text { wilderness }\end{array}$ \\
\hline
\end{tabular}

Table 2: Example acoustic objectives for outdoor spaces

\begin{tabular}{|l|l|}
\hline A & Moving water should be the dominant sound heard. \\
\hline B & A particular (iconic) sound should be clearly audible over some area. \\
\hline C & Hear, mostly, (non-mechanical, non-amplified) sounds made by people. \\
\hline D & Not be able to hear the sounds of people. \\
\hline E & The sounds of nature should be the dominant sound heard. \\
\hline F & Only the sounds of nature should be heard. \\
\hline G & Suitable to hear unamplified speech (or music). \\
\hline H & Suitable to hear amplified speech (or music). \\
\hline I & Acoustic sculpture/installation sounds should be clearly audible. \\
\hline J & Sounds conveying a city's vitality should be the dominant sounds heard. \\
\hline K & Sounds that convey the identity of place should be the dominant sounds heard. \\
\hline
\end{tabular}

